Djillali Annane

Sylvie Chevret

Jean Claude Raphael

\section{Hyperbaric oxygen therapy for acute domestic carbon monoxide poisoning: two randomized controlled trials: reply to comment by Birmingham and Hoffman}

Accepted: 14 January 2011

Published online: 25 February 2011

(C) Copyright jointly held by Springer and ESICM 2011

This reply refers to the comment available at: doi:10.1007/s00134-011-2195-3.

Dear Editor,

Drs. Birmingham and Hoffman [1]

raised some concerns about the validity of the reports from two randomized controlled trials which failed to show evidence of substantial benefit from hyperbaric oxygen therapy (HBO) for domestic carbon poisoning [2]. They argued that the main effect of HBO in case of carbon monoxide poisoning is to inhibit $\beta 2$ integrins mediated adherence of neutrophils to the injured central nervous system (CNS) endothelium, and that this effect occurs only for at least 2.8-3 ATA [3]. While this effect of exposure to oxygen seems exciting, one cannot summarize the mechanisms of carbon monoxide toxicity using neutrophil adherence to the endothelium. For patients and physicians, only clinical outcomes are of interest. Current evidence from literature does not suggest a firm and definite benefit from HBO for carbon monoxide victims [4]. The findings from our trials are in line with the conclusions of the Cochrane review [2]. Drs. Birmingham and Hoffman also highlighted that our findings were markedly different from those of Weaver and collaborators [5]. As explained in the original article, there are substantial differences between the two studies other than the plateau pressure, including different populations (mixed versus pure CO poisoning), different severity of poisoning (very few patients with loss of consciousness versus loss of consciousness as an entry criteria), different randomization method (cluster randomization versus equal proportion), blinding (double blind versus single blind), and primary outcome measure (complex set of neuropsychological tests versus self-questionnaire and thorough physical examination). In addition, the primary outcome for the Weaver trial was different in the final manuscript than reported in the earlier published description of the trial [6]. In addition, there were significantly more patients with cerebellar dysfunction at baseline in the normobaric oxygen therapy than in the experimental arm, and this condition was associated with significantly increased risk of neurological sequelae [5]. Finally, scores for neuropsychological subtests were not significantly different between groups after the first HBO session, which was conducted with a plateau pressure at 3 ATA. The difference favoring the $\mathrm{HBO}$ arm appeared after the third HBO session (the second and third sessions being conducted at 2 ATA) [5]. Thus, one may argue that the benefit from HBO was not related to the plateau pressure at 3 ATA of the first dive but rather was explained by repeating $\mathrm{HBO}$ three times. Thus, there is a need for comparing in a randomized controlled trial HBO at 3 ATA plateau pressure followed by two sessions at 2 ATA plateau pressure versus one session of HBO at 2 ATA plateau pressure, as we did.

\section{References}

1. Birmingham C, Hofmann R (2011) Comment on Annane et al.: hyperbaric oxygen therapy for acute domestic carbon monoxide poisoning: two randomized controlled trials. Intensive Care Med 37. doi:10.1007/s00134-011-2195-3

2. Annane D, Chadda K, Gajdos P, JarsGuincestre MC, Chevret S, Raphael JC (2011) Hyperbaric oxygen therapy for acute domestic carbon monoxide poisoning: two randomized controlled trials. Intensive Care Med 37:486-492. doi:10.1007/s00134-010-2093-0

3. Thom SR, Mendiguren I, Hardy K, Bolotin T, Fisher D, Nebolon M, Kilpatrick L (1997) Inhibition of human neutrophil $\beta 2$-integrin dependent adherence by hyperbaric $\mathrm{O}_{2}$. Am $\mathrm{J}$ Physiol 272:C770-C777

4. Juurlink DN, Buckley NA, Stanbrook MB, Isbister GK, Bennett M, McGuigan MA (2005) Hyperbaric oxygen for carbon monoxide poisoning. Cochrane Database of Systematic Reviews, Issue 1. Art. No.: CD002041. doi: 10.1002/14651858.CD002041.pub2

5. Weaver LK, Hopkins RO, Chan KJ, Churchill S, Elliott CG, Clemmer TP, Orme JF, Thomas FO, Morris AH (2002) Hyperbaric oxygen for acute carbon monoxide poisoning. $\mathrm{N}$ Engl $\mathrm{J}$ Med 347:1057-1067

6. Weaver LK, Hopkins RO, Larson-Lohr V, Howe S, Haberstock D (1995) Double blind, controlled, prospective, randomized clinical trial (RCT) in patients with acute carbon monoxide (CO) poisoning: outcome of patients treated with normobaric oxygen or hyperbaric oxygen $\left(\mathrm{HBO}_{2}\right)-\mathrm{an}$ interim report. Undersea Hyperb Med 22(Suppl): 14

D. Annane ( $)$ J J. C. Raphael Department of Intensive Care Medicine and Hyperbaric Oxygen Therapy, Raymond Poincaré Hospital (APHP), University of Versailles Saint Quentin en Yvelines, 104 Boulevard Raymond Poincaré, 92380 Garches, France e-mail: djillali.annane@rpc.aphp.fr

\section{S. Chevret}

Department of Biostatistics, Saint Louis Hospital (APHP), University of Paris Diderot, Avenue Claude Vellefaux, 75010 Paris, France 